\title{
Um relato sobre os desafios das atividades remotas em um curso de graduação presencial diante das medidas de prevenção contra o SARS-CoV-2
}

Clemilson Costa dos Santos - UFC - clemilson.santos@ virtual.ufc.br Emanuel Ferreira Coutinho - UFC - emanuel.coutinho@ufc.br Gabriel Antoine Louis Paillard - UFC - gabriel@ virtual.ufc.br Leonardo Oliveira Moreira - UFC - leoomoreira@ virtual.ufc.br

Resumo: O SARS-CoV-2 pertence a uma família de vírus que causam infecções respiratórias e tem se disseminado pelo mundo rapidamente. Uma das principais medidas preventivas contra a contaminação deste vírus é o isolamento social. Assim, as pessoas tem evitado sair de suas residências e algumas pessoas realizam suas atividades profissionais por meio do teletrabalho. No ensino superior, algumas universidades têm adotado atividades remotas em atividades letivas para minimizar o impacto no calendário acadêmico. No entanto, alguns cursos têm enfrentado desafios para garantir a qualidade do ensino e o princípio da isonomia. Este artigo relata alguns desafios enfrentados nas atividades remotas em um curso de graduação presencial na área de tecnologia devido à pandemia do SARS-CoV-2.

Palavras-chaves: SARS-CoV-2; curso de graduação presencial; atividades remotas.

\section{A report on the remote activities challenges in a face-to-face undergraduate course in the face of prevention measures against SARS-CoV-2}

\begin{abstract}
SARS-CoV-2 belongs to a family of viruses that cause respiratory infections and has spread worldwide quickly. One of the main preventive measures against the contamination of this virus is social isolation. Thus, people have avoided leaving their homes and some people carry out their professional activities through teleworking. In higher education, some universities have adopted remote activities in teaching activities to minimize the impact on the academic calendar. However, some courses have faced challenges in ensuring the quality of teaching and the principle of isonomy. This article reports some challenges faced in remote activities in a face-to-face undergraduate course in the technology field due to SARS-CoV-2 pandemic.
\end{abstract}

Keywords: SARS-CoV-2; face-to-face undergraduate course; remote activities.

\section{Introdução}

O SARS-CoV2 ou simplesmente novo coronavírus são denominações para um vírus pertencente a uma família de vírus que causam infecções respiratórias agudas. Este vírus em particular, que possui identificação oficial de SARS-CoV2, surgiu em Wuhan na China no final do ano de 2019 e se espalhou rapidamente para as outras províncias chinesas (LI et al., 2020). Devido ao alto grau de contágio deste vírus e a pandemia que se instalou, muitos países estão adotando medidas para conter ou reduzir o contágio. Um dos objetivos principais é impedir a propagação do vírus de pessoa para pessoa, separando os indivíduos para minimizar a transmissão.

Segundo Wilder-Smith e Freedman (2020), uma possível forma para minimizar ou interromper essa transmissão é o distanciamento social. O distanciamento social minimiza as interações entre pessoas em uma comunidade, na qual indivíduos podem ser infecciosos, mas ainda não foram identificados. Como as doenças transmitidas por 
gotículas respiratórias requerem uma certa proximidade entre pessoas, o isolamento social das pessoas reduzirá transmissão (Wilder-Smith e Freedman, 2020).

Em um site, mantido pelo governo federal, em 23 de abril de 2020, o Brasil apresenta 3.313 mortes pelo vírus, 49.492 casos de infectados pelo vírus e uma letalidade de 6,7\% (Brasil, 2020b). O distanciamento social foi a principal medida de prevenção contra a disseminação do vírus no Brasil e muitos outros países. Com isso, afetando diversos setores, tais como: indústria, educação, esporte, cultura e lazer. Em relação à educação no ensino superior, as instituições de ensino tiveram em caráter excepcional, por meio do Ministério da Educação, a possibilidade de realizarem atividades remotas servindo-se das tecnologias de informação e comunicação, nos limites estabelecidos pela legislação em vigor, em substituição às atividades presenciais letivas de alguns componentes curriculares devido à pandemia (Brasil, 2020a).

Existem cursos presenciais, como aqueles ligados à área tecnológica, que necessitam de uma infraestrutura para que os discentes possam utilizar equipamentos ou ambientes para uma melhor qualidade de ensino, aprendizagem e avaliação. Como exemplo de uma parte dessa infraestrutura, pode-se comentar sobre os laboratórios de informática que possuem computadores com recursos computacionais adequados, softwares e periféricos que são essenciais para a qualidade e atualidade de algumas disciplinas do curso. O curso, objeto de estudo deste artigo, é um curso interdisciplinar que formam bacharéis com conhecimentos especializados em duas grandes áreas principais: Sistemas Multimídia e Mídias Digitais.

Com o recente crescimento da educação à distância nas universidades, é necessário também desenvolver novas metodologias de ensino para tarefas que normalmente são desenvolvidas exclusivamente em laboratório (Destro e Iaione, 2019). Além disso, a diversidade e complexidade que caracterizam a sociedade atual provoca importantes mudanças no âmbito tecnológico no cotidiano das pessoas, elevando o grau de complexidade, dinamismo e integração do mais variados tipos de conhecimentos influenciam a educação (Nicoleti et al., 2019).

Diante do que foi exposto e levando em consideração a aplicação de atividades remotas, surgem alguns questionamentos que norteiam esta pesquisa: i) Será que é possível garantir o princípio da isonomia, onde todos os discentes possuem as mesmas oportunidades, diante do distanciamento social? ii) Será que os docentes estão preparados para essa nova forma de transmitir o conhecimento de suas disciplinas, verificando os aspectos de assiduidade e de desempenho de cada discente? iii) Será que os discentes irão consumir com qualidade o que será transmitido pelo docente?

Este artigo almeja validar se a hipótese de que atividades remotas, em substituição às atividades letivas presenciais em cursos presenciais da área de tecnologia, podem comprometer a qualidade do ensino e não contemplar o princípio da isonomia. Assim, o objetivo principal deste artigo é relatar alguns desafios enfrentados nas atividades remotas em um curso de graduação presencial na área de tecnologia devido à pandemia do SARSCoV-2. Para almejar o objetivo principal, alguns objetivos específicos foram elencados: i) elencar um conjunto de dados a serem obtidos com os docentes e compreender o impacto das atividades remotas em suas disciplinas; ii) projetar um questionário para coleta de dados sobre a opinião dos docentes sobre o impacto das atividades remotas em suas disciplinas; iii) aplicar o questionário com os docentes para cada disciplina do curso; e iv) analisar e discutir informações sobre os resultados obtidos por meio do questionário.

\section{Material e Métodos}


O objetivo principal da pesquisa, como mencionado na introdução, é revelar quais são os desafios das atividades remotas em um curso de graduação presencial diante das medidas de prevenção contra o SARS-CoV-2. Como objeto do estudo ou observação, escolheu-se um curso de graduação presencial interdisciplinar que possui uma vertente tecnológica. Adotou-se o modelo que combina uma pesquisa descritiva e uma pesquisa explicativa. Segundo Gil (2002) pesquisas descritivas objetivam a descrição das características de fenômenos em observação, ajudando a levantar opiniões. Além disso, algumas pesquisas descritivas acabam servindo para proporcionar uma nova visão do problema (Gil, 2002).

Já as pesquisas explicativas têm como objetivo testar hipóteses e identificar fatores que propiciam ao surgimento dos fenômenos, aprofundando o conhecimento da realidade em face da explicação do porquê das coisas (Gil, 2002). Gil (2002, p. 42-43) discute que uma pesquisa explicativa pode ser a continuação de uma descritiva, já que a identificação dos fatores que determinam um fenômeno precisa que este seja descrito e detalhado. Para a fase de levantamento e coleta dos dados utilizou-se o instrumento de questionário. O público-alvo, para a aplicação do questionários, foram os docentes do curso de graduação presencial supracitado.

O questionário possui como objetivo obter dados de uma disciplina, assim, se o docente está ofertando mais de uma disciplina, ele poderá responder ao questionário mais de uma vez. Na coleta dos dados, por meio do questionário, levou-se em consideração apenas as turmas de disciplinas que estavam sendo ofertadas no semestre 2020.1, pois os envolvidos nas turmas do semestre 2020.1 foram impactados pelo período de isolamento social. O questionário é composto por 12 questões, com 10 questões obrigatórias e 2 questões opcionais. As 2 questões opcionais são subjetivas e o intuito destas duas questões é obter a visão dos docentes quanto às vantagens e desvantagens em relação às atividades remotas. A Tabela 1 apresenta as perguntas do questionário, utilizado para a coleta de dados, e uma visão das possíveis respostas.

Tabela 1 - Questionário utilizado na pesquisa

\begin{tabular}{|c|c|c|}
\hline Id & Enunciado da Questão & Tipo de Resposta \\
\hline Q01 & $\begin{array}{l}\text { Qual o nome da disciplina que você irá relatar neste } \\
\text { formulário? }\end{array}$ & Subjetiva \\
\hline Q02 & $\begin{array}{l}\text { Selecione as opções utilizadas na carga horária da sua } \\
\text { disciplina? }\end{array}$ & Caixa de Seleção \\
\hline Q03 & $\begin{array}{l}\text { Sua disciplina se serve de quais ambientes para a } \\
\text { realização das aulas? }\end{array}$ & Caixa de Seleção \\
\hline Q04 & $\begin{array}{l}\text { Qual opção retrata melhor a realidade do percentual dos } \\
\text { seus discentes que possuem conectividade com a } \\
\text { Internet? }\end{array}$ & Múltipla Escolha \\
\hline Q05 & $\begin{array}{l}\text { Qual opção retrata melhor a realidade dos seus discentes } \\
\text { do percentual que possuem dispositivos, softwares e } \\
\text { equipamentos adequados para a realização das } \\
\text { atividades remotas? }\end{array}$ & Múltipla Escolha \\
\hline Q06 & $\begin{array}{l}\text { Quais das opções abaixo são utilizadas como parte do } \\
\text { conteúdo da sua disciplina? }\end{array}$ & Caixa de Seleção \\
\hline Q07 & $\begin{array}{l}\text { Quais das opções abaixo são utilizadas como parte da } \\
\text { avaliação da sua disciplina? }\end{array}$ & Caixa de Seleção \\
\hline Q08 & $\begin{array}{l}\text { Você concorda que sua disciplina poderia ser ministrada } \\
\text { como atividades remotas sem comprometer os aspectos } \\
\text { de qualidade do ensino e o princípio da isonomia? }\end{array}$ & $\begin{array}{l}\text { Múltipla Escolha } \\
\text { (escala Likert) }\end{array}$ \\
\hline
\end{tabular}

V. $18 \mathrm{~N}^{\mathrm{o}} 1$, julho, 2020 RENOTE

DOI: 


\begin{tabular}{|l|l|l|}
\hline Q09 & $\begin{array}{l}\text { Em relação à assiduidade dos discentes nas atividades } \\
\text { remotas, você concorda que possui uma metodologia ou } \\
\text { estratégia para a verificação da assiduidade dos seus } \\
\text { discentes? }\end{array}$ & $\begin{array}{l}\text { Múltipla Escolha } \\
\text { (escala Likert) }\end{array}$ \\
\hline Q10 & $\begin{array}{l}\text { Em sua opinião, quais os maiores impedimentos que os } \\
\text { discentes enfrentariam na realização das atividades } \\
\text { remotas? }\end{array}$ & Caixa de Seleção \\
\hline Q11 & Quais as vantagens em relação às atividades remotas? & Subjetiva \\
\hline Q12 & $\begin{array}{l}\text { Quais as desvantagens em relação às atividades } \\
\text { remotas? }\end{array}$ & Subjetiva \\
\hline
\end{tabular}

Para a elaboração e aplicação do questionário utilizou-se o Google Forms, pois a tecnologia colabora para a aplicação deste instrumento diante do isolamento social. As questões obrigatórias Q08 e Q09 utilizaram a escala Likert como possibilidade de resposta. A escala Likert é uma maneira de medir o nível de concordância ou não a uma dada afirmação, servindo-se de opções de resposta em níveis possuem extremos (Paillard e Moreira, 2017). Um esquema de respostas para uma questão na escala Likert é: i) Discordo totalmente; ii) Discordo parcialmente; iii) Indiferente; iv) Concordo parcialmente; e v) Concordo totalmente.

Um aspecto motivador para a elaboração deste questionário é que tanto os docentes quanto o Centro Acadêmico do curso fizeram pesquisas e consultas com os discentes sobre a problemática relatada neste artigo. Tais pesquisas e consultas feitas pelos docentes e pelo Centro Acadêmico do curso ajudaram na elaboração do questionário apresentado na Tabela 1. O questionário ficou disponível pelo período de uma semana para alcançar um número maior de participantes docentes. É válido ressaltar que o questionário foi aplicado de forma anônima e nenhum dado sensível, que revelasse o docente, foi coletado.

\section{Resultados e Discussão}

No total houveram 36 respostas, onde cada resposta retrata a visão do docente sobre o contexto de uma determinada disciplina e seus discentes. Como dito, o curso de graduação, objeto do estudo, possui disciplinas das áreas de Tecnologias Digitais. Das 36 respostas, 12 disciplinas faziam parte da área de Sistemas Multimídia, 8 disciplinas da área de Mídias Digitais e 16 disciplinas que são gerais ou particulares do próprio curso. Disciplinas como introdução ao curso, trabalho de conclusão do curso e metodologia da pesquisa científica são disciplinas consideradas particulares ou gerais.

A questão Q02 tem como objetivo coletar informações sobre a carga horária das disciplinas e conhecer sobre a necessidade de artefatos para a realização de atividades práticas. Diante dos resultados coletados foi informado que: i) 3 disciplinas são totalmente teóricas; ii) 7 disciplinas são totalmente práticas; e iii) 26 disciplinas possuem etapas teóricas e práticas. Por meio dos resultados da amostra obtida, pode-se perceber que o curso tem um alto teor de praticidade na transmissão dos conhecimentos.

Já a questão Q03 visa obter informações sobre quais ambientes, físicos ou digitais, são utilizados para a realização das aulas na disciplina. Essa questão foi colocada no questionário como "Caixa de Seleção", onde o docente poderia selecionar mais de um ambiente. Além disso, existia a opção "Outros", onde o docente poderia descrever um ambiente que não foi previsto no questionário. A Figura 1 apresenta um histograma com o quantitativo de ambientes que foram relatados pelos docentes. É válido ressaltar que uma disciplina pode se servir de mais de um ambiente. Foi observado, por meio dos 
resultados, que turmas diferentes de uma mesma disciplinas utilizam ambientes diferentes.

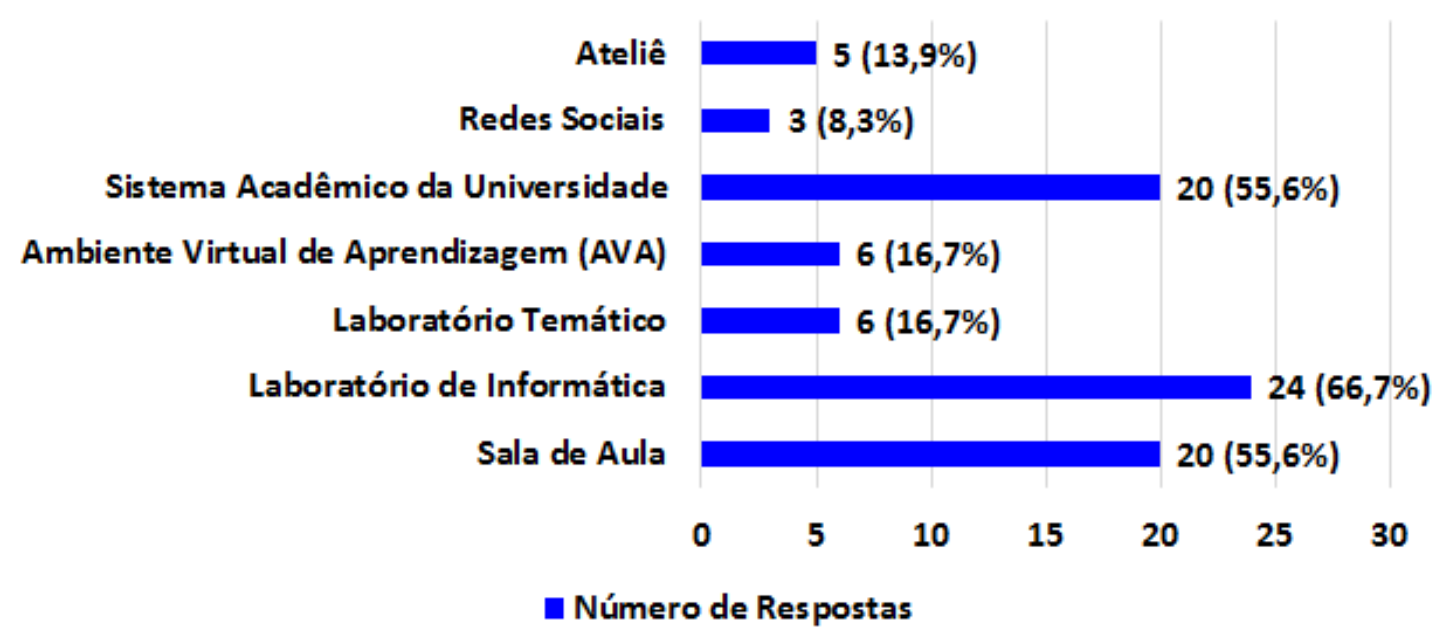

Figura 1 - Quantitativo de Ambientes relatados pelos Docentes

Explorando ainda mais resultados da questão Q03, sumarizados na Figura 1, foi observado que apenas 2 docentes utilizam somente a sala de aula como ambiente. Outra observação importante é que 10 docentes relataram que utilizam a combinação de, pelo menos, sala de aula e laboratório de informática como ambiente para a realização de suas aulas. Ainda nos resultados, observou-se que houveram 2 docentes que utilizam somente laboratório de informática como ambiente.

Na Figura 1 observa-se um ambiente denominado laboratório Temático onde houveram 6 ocorrências relatadas pelos docentes. O laboratório temático é um espaço específico para práticas de determinadas disciplinas, são exemplos de tais laboratórios: laboratório de audiovisual, laboratório de tecnodocência, laboratório de sistemas multimídia, laboratório de usabilidade, laboratório de jogos e laboratório de computação física. O ateliê foi outro ambiente citado nos resultados da questão Q03 onde são realizadas práticas artísticas, onde 5 docentes relataram que utilizam pelo menos o ateliê em suas atividades.

Se levarmos em consideração que 24 docentes relataram que se servem de laboratórios de informática e 6 docentes utilizam laboratórios temáticos, é mostrado que 30 das 36 respostas apontam que o curso necessita de uma infraestrutura particular para que os conteúdos de suas disciplinas sejam transmitidos com qualidade. O sistema acadêmico da universidade foi apontado por 20 docentes, sendo considerado o ambiente oficial da universidade para interação entre o docente e discentes fornecendo funcionalidades para troca de mensagens, entrega de atividades, fóruns, acompanhamento do desempenho discente, materiais didáticos etc. Outros ambientes citados na pesquisa foram os ambientes virtuais de aprendizagem (AVA) e as redes sociais. Apesar do baixo número de citação destes últimos ambientes, eles servem como ambientes complementarem aos demais.

A questão Q04 tem como objetivo obter informações sobre o percentual de discentes, na percepção do docente, que possuem conectividade com a Internet. A realização de atividades remotas requer, no mínimo, que o discente possua conectividade com a Internet para que possam consumir o conhecimento de diversas formas, por exemplo assistir videoaulas, realizarem webconferências, troca de e-mails, efetuar download de materiais didáticos etc. 
De acordo com os resultados apresentados na Figura 2: i) 1 (2,8\%) docente relatou que entre 0 a $25 \%$ dos seus discentes possuem conectividade com a Internet; ii) $5(13,9 \%)$ docentes apontaram que entre 26 a $50 \%$ dos seus discentes possuem conectividade com a Internet; iii) $11(30,6 \%)$ docentes indicaram que entre 51 a $75 \%$ dos seus discentes possuem conectividade com a Internet; iv) 9 (25\%) docentes apontaram que entre 76 a $100 \%$ dos seus discentes possuem conectividade com a Internet; e v) $10(27,8 \%)$ docentes não souberam responder a essa questão. Diante dos resultados, pode-se perceber que não pode ser cumprido o princípio da isonomia, pois existe uma alta probabilidade de discentes que não poderiam acompanhar, com qualidade, as atividades remotas devido à ausência de conectividade com a Internet.

O objetivo da questão Q05 é obter informações sobre a visão do docente em relação ao percentual de seus discentes que possuem dispositivos, softwares e equipamentos adequados para a realização de atividades remotas. Aqui vale destacar que o curso tem um percentual alto de disciplina práticas que necessitam de uma infraestrutura particular, como mostrado nas questões supracitadas. Assim, existem dispositivos que devem ter requisitos mínimos para que as práticas ocorram com qualidade, licenças de software e outros equipamentos que são da natureza das disciplinas.

Em tese, para que não impacte na qualidade da transmissão do conhecimento, os discentes deveriam ter acesso a essa infraestrutura em casa para a realização das atividades remotas. É válido ressaltar, que algumas disciplinas práticas necessitam de poucos recursos, já outras necessitam de vários desses recursos apontados. A Figura 3 apresenta os resultados percentuais apontados pelos docentes.

Diante dos resultados percebe-se que: i) $4(11,1 \%)$ docentes relataram que entre 0 a $25 \%$ dos seus discentes possuem infraestrutura necessária; ii) $6(16,7 \%)$ docentes apontaram que entre 26 a 50\% dos seus discentes possuem infraestrutura necessária; iii) $9(25 \%)$ docentes indicaram que entre 51 a $75 \%$ dos seus discentes possuem infraestrutura necessária; iv) $7(19,4 \%)$ docentes apontaram que entre 76 a $100 \%$ dos seus discentes possuem infraestrutura necessária; e v) 10 (27,8\%) docentes não souberam responder a essa questão. Em relação às atividade remotas e levando em consideração os resultados obtidos na questão Q05, existe uma parcela dos discentes não teriam acesso a uma infraestrutura de qualidade para acompanhar a transmissão do conteúdo e também realizar as atividades práticas.

\section{Qual opção retrata melhor a realidade do percentual dos seus discentes que possuem conectividade com a Internet?}

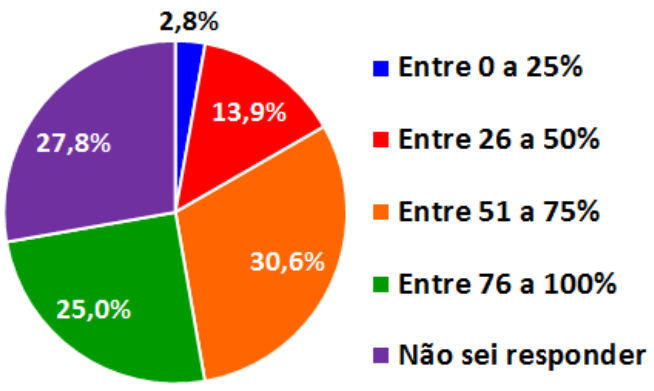

Figura 2 - Resultados da Questão Q04
Qual opção retrata melhor a realidade dos seus discentes do percentual que possuem dispositivos, softwares e equipamentos adequados para a realização das atividades remotas?
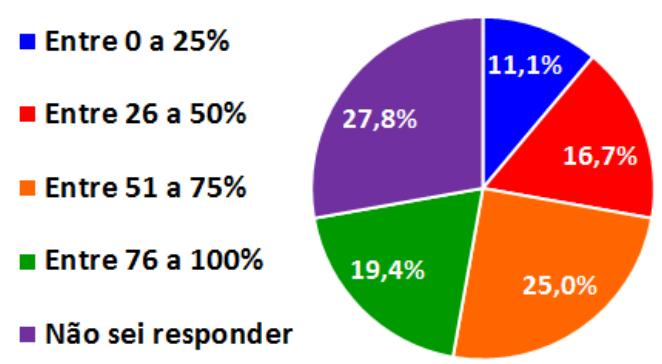

Figura 3 - Resultados da Questão Q05 
Q06 tem como objetivo descobrir o que é utilizado, pelo docente, como parte do conteúdo em suas disciplinas. É válido ressaltar que na questão o docente poderia informar mais de uma opção. De acordo com os resultados: i) $22(61,1 \%)$ docentes informaram que utilizam livros; ii) $33(91,7 \%)$ docentes informaram que adotam slides; iii) $20(55,6 \%)$ docentes relataram que utilizam infraestrutura de recursos computacionais para desenvolvimento e modelagem de sistemas; iv) 9 (25\%) docentes apontaram que utilizam dispositivos eletrônicos como tablets, câmeras, mesas digitalizadoras etc.; v) 15 $(41,7 \%)$ docentes expuseram que utilizam metodologias para observação em loco, onde necessita que o discente esteja no modo presencial; vi) $11(30,6 \%)$ docentes indicaram que utilizam material ou estrutura para desenho, prototipação e/ou ilustração; e vii) 11 $(30,6 \%)$ docentes apontaram que utilizam fóruns, chats e/ou redes sociais. Devido às características práticas do curso nota-se que a utilização de equipamentos e os meios digitais são conteúdos predominantes no curso. As informações obtidas na questão Q06 reforçam que, para consumir muitos destes conteúdos, conectividade com a Internet e infraestrutura são essenciais.

Já a questão Q07 tem como objetivo obter informações sobre como a avaliação é realizada nas disciplinas pelos docentes. É válido ressaltar que no questão o docente poderia informar mais de uma opção. Diante dos resultados obtidos: i) $11(30,6 \%)$ dos docentes utilizam provas escritas; ii) $2(5,6 \%)$ dos docentes adotam provas online; iii) 33 $(91,7 \%)$ dos docentes relataram que passam trabalhos práticos; e iv) $4(11,1 \%)$ docentes fazem avaliação por meio de mensagens de chat, fóruns e redes sociais. Por meio dos resultados, pode-se perceber que os docentes teriam problemas com atividades remotas, pois a maioria adota trabalhos práticos. Então, no mínimo, uma infraestrutura mínima seria necessária para a realização destes trabalhos por parte dos discentes.

O objetivo da questão Q08 é obter o nível de concordância que o docente tem sobre a possibilidade de ministrar sua disciplina com atividade remotas sem comprometer os aspectos de qualidade do ensino e o princípio da isonomia. Por meio da Figura 4, que apresenta os resultados obtidos, pode-se perceber que: i) $14(38,9 \%)$ docentes discordam totalmente; ii) $4(11,1 \%)$ docentes discordam parcialmente; iii) $1(2,8 \%)$ docente diz que é indiferente; iv) 14 (38,9\%) docentes concordam parcialmente; e v) $3(8,3 \%)$ docentes concordam totalmente. Diante disso, pode-se observar a metade dos docentes estão no nível de discordância. Tal discordância pode impactar negativamente na aplicabilidade das atividades remotas, pois muitos docentes sentem que o ensino pode ser prejudicado e também o princípio da isonomia não seria garantido.

Você concorda que sua disciplina poderia ser ministrada como atividades remotas sem comprometer os aspectos de qualidade do ensino e o princípio da isonomia?

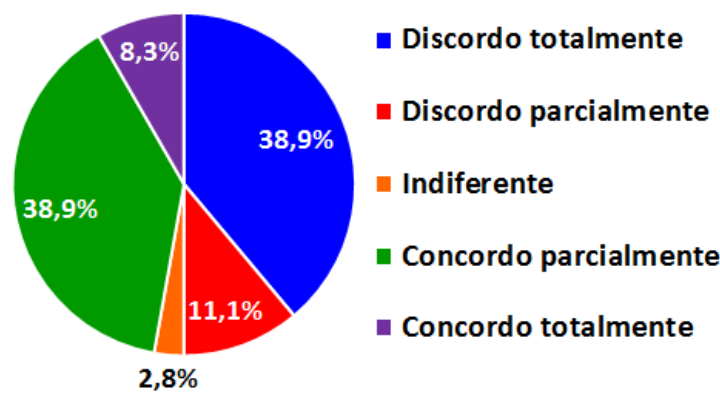

Figura 4 - Resultados da Questão Q08
Em relação à assiduidade dos discentes nas atividades remotas, você concorda que possui uma metodologia ou estratégia para a verificação da assiduidade dos seus discentes?

- Discordo totalmente

- Discordo parcialmente

- Indiferente

- Concordo parcialmente

- Concordo totalmente

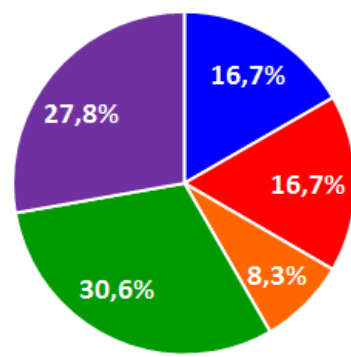

Figura 5 - Resultados da Questão Q09

V. $18 \mathrm{~N}^{\mathrm{o}}$ 1, julho, 2020 RENOTE DOI: 
Já a questão Q09 visa obter informações sobre a concordância que o docente possui em uma metodologia ou estratégia para acompanhar a assiduidade dos discentes. Pela Figura 5, que apresenta as informações obtidas, pode-se perceber que: i) $6(16,7 \%)$ docentes discordam totalmente; ii) $6(16,7 \%)$ docentes discordam parcialmente; iii) 3 $(8,3 \%)$ docentes dizem que é indiferente; iv) 11 (30,6\%) docentes concordam parcialmente; e v) $10(27,8 \%)$ docentes concordam totalmente. Por meio destes resultados pode-se perceber que os docentes a maioria tendem a concordar com questão. No entanto, é válido ressaltar que a verificação da assiduidade pode estar ligada à questão do acompanhamento do rendimento dos discentes em atividades remotas. Portanto, para isso, é necessário que as atividades remotas aconteçam com qualidade e contemplem o princípio da isonomia.

A questão Q10 tem como objetivo obter as opiniões dos docentes sobre quais os maiores impedimentos que os discentes teriam na realização das atividades remotas. É importante ressaltar que, nesta questão, o docente pode informar mais de uma opção. De acordo com os resultados os maiores impedimentos seriam: i) $33(91,7 \%)$ docentes apontaram a ausência ou baixa conectividade com a Internet; ii) 31 (86,1\%) docentes relataram sobre a falta de um ambiente familiar propício para a realização das atividades remotas; iii) 19 (52,8\%) docentes informaram sobre a ausência de materiais, ferramentas e dispositivos eletrônicos; iv) recursos computacionais inadequados e/ou ausência softwares necessários para realização das atividades remotas; e v) $22(61,1 \%)$ docentes apontaram a falta de hábito com modelo de atividades remotas e/ou a dificuldade de não ter um docente presencial para as orientações nestas atividades. Um impedimento que chamou a atenção e que foi levantado na opção "Outros", onde o docente poderia expor algo que não estivesse entre as opções, são as questões psicológicas dos discentes nesta época de pandemia, alguns docentes relatam que isso pode ser um aspecto que pode impactar negativamente no aprendizado.

A questão opcional e subjetiva Q11 visa obter informações sobre a percepção dos docentes quanto às vantagens em relação às atividades remotas. Houveram 33 respostas no total e os relatos mais recorrentes são: i) flexibilidade de tempo e horário para interação com o curso; ii) maior desenvolvimento da autonomia do discente no processo de aprendizagem; iii) diminuição da ociosidade dos discentes, ocupando a mente dos mesmos; iv) maior conforto, comodidade e segurança pessoal; v) o não comprometimento do calendário acadêmico; e vi) manter a comunicação com os discentes e deixá-los ainda refletindo sobre os temas abordados na disciplina.

Já questão opcional e subjetiva Q12, última questão do questionário, tem como objetivo perceber a opinião dos docentes quanto às desvantagens em relação às atividades remotas. No total, houveram 32 respostas e os relatos mais comuns são: i) não é o modelo de aula ideal para a disciplina; ii) não contempla o princípio da isonomia, excluindo alguns discentes; iii) falta de equipamentos e conectividade por parte dos discentes e docentes; iv) possível perda do foco e falta de autonomia por parte dos discentes, pois o momento é complicado para alguém se concentrar e se dedicar nas atividades; v) falta da interação pessoal com o docente e com os demais colegas no momento de desenvolver soluções para os problemas propostos; vi) falta maior de acompanhamento, por parte do docente, das atividades adotadas na atual metodologia de ensino da disciplina; vii) alguns discentes relataram que não tem ambiente propício em casa para aulas; e viii) os materiais didáticos da disciplina necessitariam de uma reformulação para serem ministrados como atividades remotas.

Ao considerar a flexibilidade como uma vantagem, a condução de turmas de disciplinas práticas pode se beneficiar. A pesquisa constatou a existência de 33 disciplinas 
com um percentual prático em suas conduções. A flexibilização tanto de horários quanto de ferramentas pode auxiliar na execução de tarefas e práticas laboratoriais que não poderiam ser realizadas na universidade. Por outro lado, como muitos docentes indicaram que necessitam de laboratórios de informática e temáticos para suas aulas, dependendo do software necessário, a atividade remota pode ser inviabilizada.

É recorrente que a falta ou dificuldade de conectividade à Internet pode prejudicar ou mesmo inviabilizar qualquer iniciativa remota, ainda mais em cursos que utilizam muito de recursos tecnológicos. Isto levanta a questão que o discente, para plena participação e aprendizado nas atividades remotas, deveria possuir a infraestrutura necessária para garantir a isonomia e aprendizagem. Porém, sabe-se que essa não é a realidade de muitos. Pelas respostas da pesquisa, 25\% dos docentes sinalizaram que mais de $75 \%$ de seus discentes possuem acesso a conexão, mas 30,6\% dos docentes indicaram que menos que $50 \%$ de seus discentes possuem conexão com Internet. Isto é um problema vital para a realização de atividades remotas. Adicionalmente, o ambiente no qual o discente se encontra pode não ser propício ao estudo e concentração requerida para tais práticas. Alguns docentes relataram que seria uma vantagem o maior conforto e comodidade dos alunos realizando atividades em seu ambiente familiar. Porém isso é uma contradição com a desvantagem de ambiente não habilitado para estudos, sinalizado por alguns docentes.

Outra grande dificuldade é a adaptação dos materiais tradicionais das aulas para esta modalidade remota. Por exemplo slides, onde $91,7 \%$ dos docentes informaram que os utilizam nas aulas. A adaptação didática do material não é uma tarefa fácil, requerendo esforço e tempo. Além disso, as atividades e exercícios, teóricos ou práticos, também devem ser adequadas para que possam ser executadas corretamente. Isto também implica na maneira de acompanhar o discente nas atividades remotas, tanto do ponto de vista de assiduidade quanto de desenvolvimento das atividades.

Outro ponto muito importante, que também sempre é discutido em aulas presenciais, é a didática do docente. A maneira na qual ele expressa conceitos, motiva discentes (e se auto motiva) e equilibra teoria com prática são exemplos de como o docente lida com a didática. Em atividades remotas, onde a interação presencial é nula, no máximo visualizando por meio de uma câmera, o foco se perde facilmente. E esta transição de aula presencial para aula remota também provoca uma mudança de comportamento do docente em relação ao seu modo de lecionar.

Por fim, as avaliações em turmas remotas podem ser realizadas de diversas maneiras: fóruns, chats, uploads de trabalhos, provas online etc. A pesquisa apontou que 91,7\% dos docentes utiliza trabalhos práticos, 11,1\% utiliza recursos de redes sociais, chats e fóruns, e apenas 5,6\% provas online. Porém, deve-se tomar cuidado em medir o real aprendizado, que por si só já é um desafio natural do docente.

\section{Conclusões}

Este artigo apresentou um relato, por meio de uma pesquisa, sobre os desafios das atividades remotas em um curso de graduação presencial diante das medidas de prevenção contra o SARS-CoV-2. Esta pesquisa provocou três perguntas norteadoras no intuito de validar ou refutar a hipótese formulada na introdução. Respondendo a primeira pergunta viu-se que não seria possível garantir o princípio da isonomia, visto que existiam discentes sem ou com baixa conectividade com a Internet e, além disso, muitos também não possuíam uma infraestrutura adequada para as atividades remotas. Já com relação à segunda pergunta, foi visto que os docentes não estão seguros com essa nova forma de transmissão do conhecimento, verificação do desempenho e assiduidade dos discentes. 
Por fim, respondendo à terceira pergunta, foram relatados vários impedimentos que poderiam impactar no consumo do conhecimento, com qualidade, por parte do discente. Nesta última questão, aspectos de infraestrutura, conectividade, hábito, aspectos psicológicos e outros foram levantados.

Assim, a hipótese de que atividades remotas, em substituição às atividades letivas presenciais em cursos presenciais da área de tecnologia, podem comprometer a qualidade do ensino e não contemplar o princípio da isonomia foi comprovada no contexto e amostra que foi realizado o estudo. Como trabalhos futuros almeja-se: i) realizar uma pesquisa mais aprofundada e com um número maior de amostra e questões norteadoras; ii) aplicar uma pesquisa similar com cursos presenciais de outras áreas; e iii) realizar uma pesquisa para coletar também a visão do discente e confrontar os resultados com a presente pesquisa.

\section{Referências Bibliográficas}

BRASIL. Ministério da Educação. Gabinete do Ministro. Portaria no 343, de 17 de março de 2020. Dispõe sobre a substituição das aulas presenciais por aulas em meios digitais enquanto durar a situação de pandemia do Novo Coronavírus - COVID-19. Diário Oficial da União, Brasília, DF, n. 53, 18 mar. 2020. Seção 1, p. 39.

BRASIL. Ministério da Saúde. Coronavírus Brasil. Disponível em: <https://covid.saude.gov.br>. Acesso em: 23 abr. 2020.

DESTRO, F. H. T.; IAIONE, F. Desenvolvimento de Laboratório Remoto Utilizando Módulo Didático para Ensino de Microcontroladores. In: VIII Congresso Brasileiro de Informática na Educação - XXX Simpósio Brasileiro de Informática na Educação (SBIE 2019). 2019.

GIL, Antonio Carlos. Como Elaborar Projetos de Pesquisa. São Paulo: Atlas, 2002.

LI, R.; PEI, S.; CHEN, B.; SONG, Y.; ZHANG, T.; YANG, W.; SHAMAN, J. Substantial undocumented infection facilitates the rapid dissemination of novel coronavirus (SARSCoV2). Science, Washington, mar. 2020. Research Article. Disponível em: $<$ https://science.sciencemag.org/content/early/2020/03/24/science.abb3221/>. Acesso em: 21 abr. 2020.

NICOLETI, P. C.; JUNIOR, E. T. O.; CRISTIANO, M. A.; TAROUCO, L. M. R.; VILA, E.; SILVA, J. B. Estudo Exploratório sobre Realidade Aumentada e Laboratório Remoto no Ensino de Física. Revista Novas Tecnologias na Educação (RENOTE). v.17, n.3. 2019.

PAILLARD, G. A. L.; MOREIRA, L. O. O impacto dos paradigmas e linguagens de programação no ensino intermediário da programação de computadores. Revista Tecnologias na Educação, v.19, n.9, jul. 2017.

WILDER-SMITH, A.; FREEDMAN, D. O. Isolation, quarantine, social distancing and community containment: pivotal role for old-style public health measures in the novel coronavirus (2019-nCoV) outbreak. Journal of Travel Medicine. v.27, n.2, fev. 2020. 